\title{
Cross wavelet analysis between groundwater level, precipitation, and temperature in Chaiwopu Basin
}

\section{FENG Wei ${ }^{1,2, ~ a, ~ R E N ~ S h u a i b i n ~ 3, ~ b, ~ Y I N ~ X i u l a n ², ~ c ~}$, ZHU Juyan², d, LI Haitao 2, e}

${ }^{1}$ School of Water Resources and Environment, China University of Geosciences, Beijing ,China;

${ }^{2}$ China Institute of Geo-Environment Monitoring, Beijing, China;

${ }^{3}$ Xinjiang Institute of Geo-Environment Monitoring, Urumqi, China ;

afengw@mail.cigem.gov.cn, ${ }^{\mathrm{b}} \underline{411289433 @ q q . c o m},{ }^{\circ}$ yinxl@mail.cigem.gov.cn@mail.cigem.gov.cn, dzhujy@mail.cigem.gov.cn, ${ }^{\mathrm{e}}$ liht@mail.cigem.gov.cn

Keywords: Water table, Precipitation, Temperature, Wavelet analysis, Periodicity, Chaiwopu Lake Abstract: Utilize the senior sequences from 2004 to 2016 of the 4 groundwater monitoring holes around Chaiwopu Lake in Xinjiang to observe the water level, precipitation and temperature, then use continuous wavelet and cross wavelet transform method to analyze the periodicity of water level, precipitation and temperature, and the correlation between each other. The results show that (1) the main fluctuation period of groundwater level of Chaiwopu Lake, precipitation and temperature, and the resonance period between them both are 1 years. (2) The groundwater level time-lag of phreatic water is less than that of confined water. (3) The time-lag between precipitation and groundwater level is greater than that between temperature and groundwater level. Through this mathematical statistics, we can almost master the time-lag relationship between the groundwater level with precipitation and temperature, in the later study, it is necessary to strengthen the analysis to the physical mechanism of the interaction between the three factors.

\section{Introduction}

Chaiwopu Lake is located in the Chaiwopu Basin of the Urumqi River Basin, is a typical inland lake in arid area[1], which is obviously affected by climate, where small fluctuations in climate can cause significant fluctuations [2]. In 1990s, as one of the main water sources in Urumqi, Chaiwopu Lake was over exploited. The groundwater level continued to decline and the water quality deteriorated seriously. In 2000, the Three Mountains Water Diversion Project was launched in Urumqi, which once improved the environmental conditions of Chaiwopu Lake and the lake showed a beautiful scenery to people again[3]. In recent years, the precipitation in in Chaiwopu Basin drastically reduced, the water level obviously decreased from 2010 to May 2016, the lake surface was shrank from 27 square kilometers in 2008 to 14 square kilometers [4], with half becoming saline and alkaline land, changes of it for many years can be seen from the visible remote sensing images in 2010 and 2014 (Fig. 1).

Atmospheric precipitation and temperature are two important indexes of climate change in inland area, which directly affect shallow groundwater level and surface water. The effects of atmospheric circulation characteristics on temperature, precipitation and humidity are significant in arid and semi-arid regions of Northwest China. The inter-annual to inter-decadal periods of temperature and precipitation are controlled by large-scale circulation characteristics. [5] The positive position of the PDO index corresponds to the drought period in the eastern part of Northwest China, and the negative position corresponds to the wet period [6]. A correlation 
relationship exists between the extreme temperature of Chaiwopu Basin in Xinjiang and Arctic Oscillation (AO) [7]. Combining with the change of groundwater level, the relationship between groundwater level and climate index is analyzed, which is of great significance for rational exploitation of groundwater resources. The widely used time-lag analysis method of time series is the cross wavelet transform method developed by wavelet analysis [8-10]. This method is also widely used in the field of groundwater, such as precipitation-runoff analysis, [11], groundwater level prediction, [12], water level and precipitation, the correlation of meteorological models, [13-19] and other research fields.

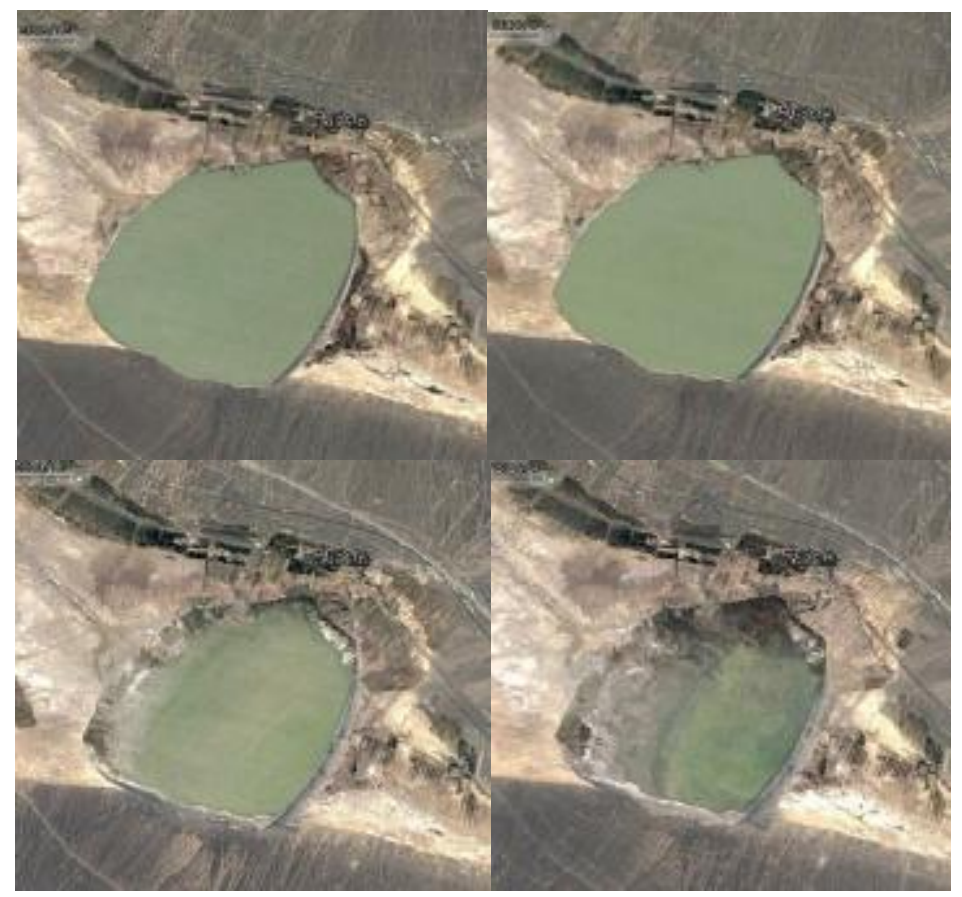

Note:Images sourced from GOOGLE EARTH.Upper left is the lake image in 2008,Upper right is the lake image in 2010,Lower left is the lake image in 2014,Lower right is the lake image in 2016

Fig.1 Comparison of remote sensing images of Chaiwopu Lake in different years

The precipitation in the basin, especially the precipitation in the upstream mountain, and the snow melt in mountain regions (affected by the temperature dynamic) jointly form the recharge on the groundwater level, therefore based on continuous wavelet transform, cross wavelet transform between the precipitation and groundwater level, temperature and groundwater level are carried out respectively in this paper, to analyze the time-lag characteristics of the resonance period and water level on precipitation and temperature.

\section{Research Method}

Wavelet analysis was adopted in this paper, including Continuous Wavelet Transform (CWT), Cross Wavelet Transform (XWT) and Wavelet Coherence (WTC). The idea behind the CWT is to apply the wavelet as a bandpass filter to the time series. The wavelet is stretched in time by varying its scale. XWT reveals areas with high common power while WTC reveals how coherent the XWT is in time frequency space as another useful measure. The methods and computer program are from Torrence and Compo [4], and Grinsted et al. [5]. 


\section{General Situations of Study Region}

Chaiwopu Lake is located in Chaiwopu basin, south of the Daxigou Mizoguchi, north to the Wulabo Reservoir Dam, east to the Salt Lake. The sedimentation in the basin with quaternary pebble, gravel, sand and gravel and silty loam of tens of meters to more than 800 meters thick, creates a good space condition for the groundwater storage, which is the distribution area that rich in phreatic water and confined water and artesian water in small area [20]. Located in the eastern side of Chaiwopu Basin and the westside of the Salt Lake, the lake area is $25 \mathrm{Km}^{2}$, the average water depth is $4.2 \mathrm{~m}$, the maximum water depth is $6 \mathrm{~m}$, the water storage capacity is $1.26 * 108 \mathrm{~m}^{3}$, and the degree of mineralization is 5-6 g/L. It is a saltwater lake. The lake is mainly recharged by the spring from the north and west of the lake, the overflow of the phreatic water and confined water in the lake district, consumed by evaporation from the lake surface, with an annual average amplitude range of $0.47-0.7 \mathrm{~m}$ of water level (Fig. 2).

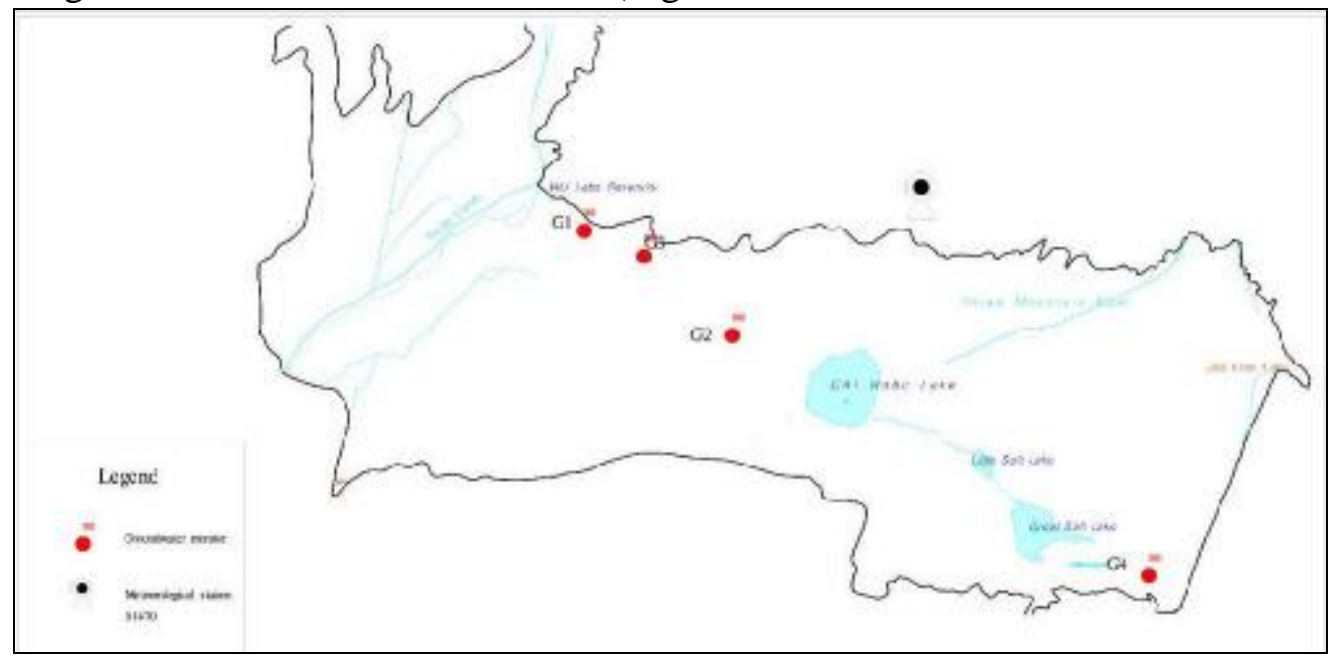

Fig.2 Distribution map of study area location and groundwater monitoring points

\section{Data Sources and Preprocessing}

\section{Data Sources}

(1) Groundwater dynamic monitoring data

The long time dynamic monitoring data of 4 groundwater level monitoring holes around the lake is used in this paper (Tab. 1). For the lack of individual data, the interpolation method is adopted (Fig. 3). The monitoring layer of each monitoring hole is a loose rock porous aquifer. The monitoring time is from January 2004 to May 2016, obtaining the groundwater level dynamic data of total 149 months.

Tab.1 Basic information of groundwater monitoring holes

\begin{tabular}{cccc}
\hline$\#$ & Location & Depth of well & Groundwater hydraulic type \\
\hline G1 & East of health bureau farm & 92 & Confined water \\
G2 & Station of Sangezhuang Village & 80 & Confined water \\
G3 & Chaiwopu tree farm & 41 & Phreatic water \\
G4 & South of Wuku Road & 97 & Phreatic water \\
\hline
\end{tabular}


(2) Meteorological data

Meteorological data is for the monthly data (Fig. 4) of Xinjiang Tianchi Station (station number: 51470), comes from China Meteorological Data Website (http://data.cma.gov.cn/). The annual average precipitation of Tianchi Station from 2009 to 2015 is $611.6 \mathrm{~mm}$ (fig.4). Tianchi is located at the elevation of $2000 \mathrm{~m}$ mountain, the annual average temperature is $2.3^{\circ} \mathrm{C}$ for many years (fig.5).

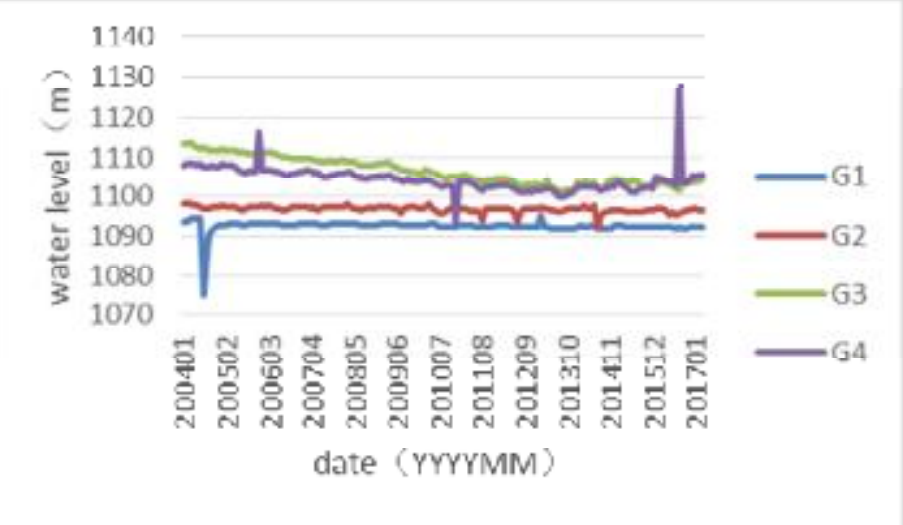

Fig.3 Groundwater dynamic curve diagram of monitoring holes

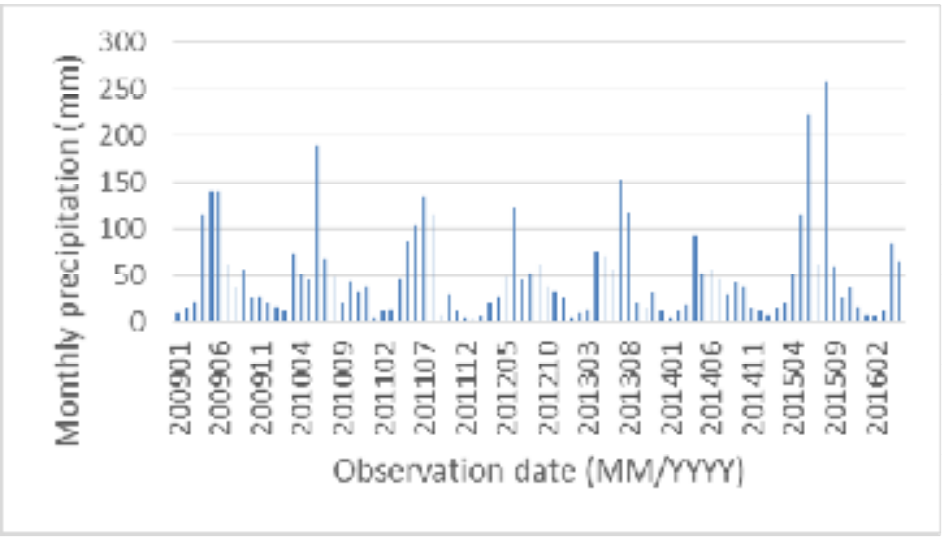

Fig.4 Monthly precipitation data of Tianchi Station

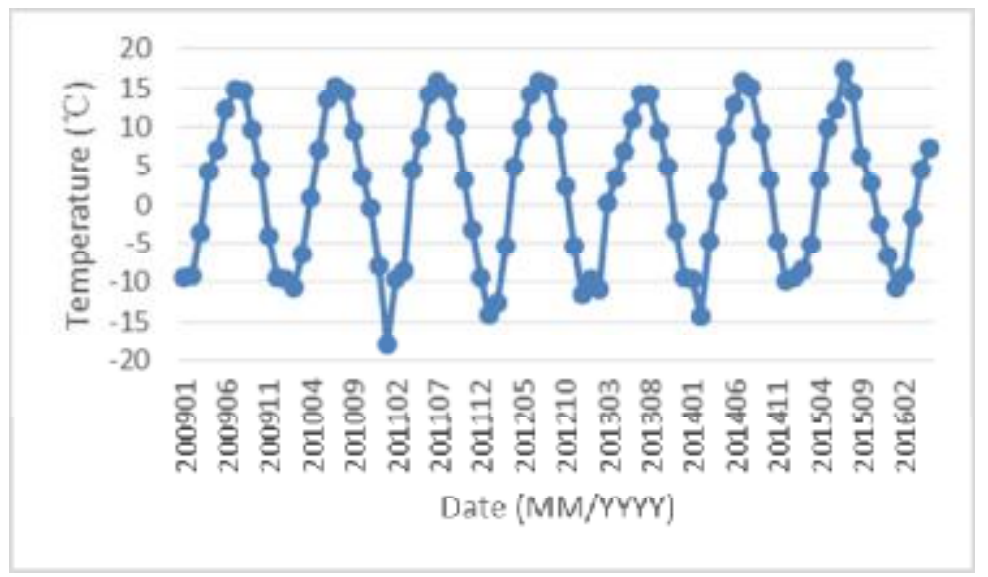

Fig.5 Monthly temperature data of Tianchi Station

\section{Results and Analysis}

\section{Continuous Wavelet Transform}

The water level dynamic, precipitation $(\mathrm{P})$ and monthly temperature values of each monitoring 
hole in the study area were analyzed by continuous wavelet transform (Fig. 6), in order to analyze the main fluctuation period and significant time bucket.
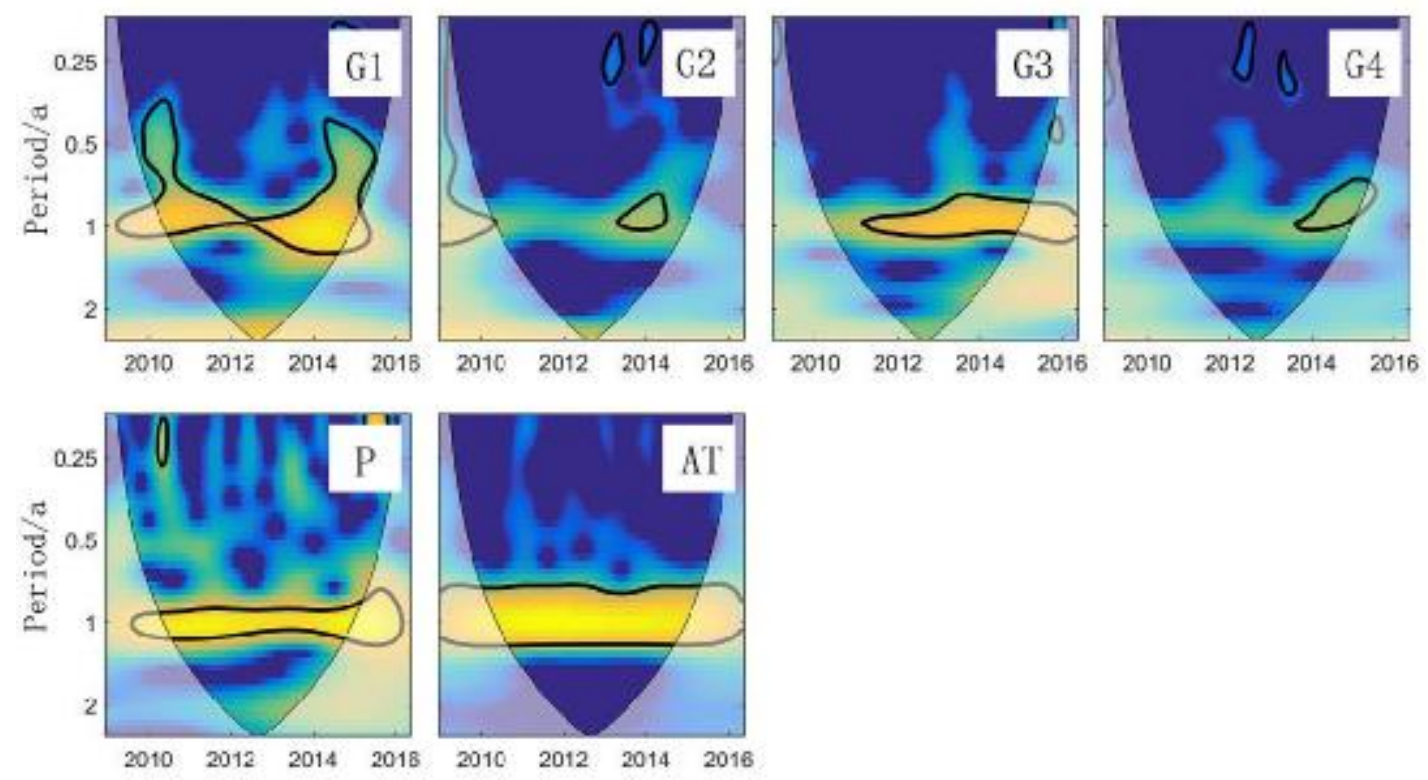

Note: Yellow and blue in the figures indicate the peak and valley values of energy density, and color indicates the relative change of energy density. The closed area circled by the black thick line has passed the standard red noise test at $95 \%$ confidence level. The cone area below the black thin lines is the cone of influence (COI) region, affects a larger area affected by the wavelet transform data edge effect.

Fig.6 Continuous wavelet transforms of each elements

As it can be seen from Fig. 6, generally, the monthly value series of groundwater level, precipitation and temperature have a main fluctuation period of about 1 year. The significant time buckets of each time series data are not consistent through the standard red noise test at $95 \%$ confidence level, in which the continuity of precipitation and temperature is strong, and the groundwater level is the second. Except COI, the significant periods of precipitation and temperature were continuously distributed; G1 water level is also continuous; the significant period of G2 hole is from May 2013 to July 2014; the significant period of G3 hole is from March 2011 to May 2016; and the significant period of G4 hole is from August 2013 to July 2015.

\section{Cross Wavelet Transform of Precipitation and Groundwater Level}

The cross wavelet transform of the groundwater level of each monitoring hole between the precipitations is carried out to analyze its resonance period, significant time bucket and phase relationship (Fig. 7). 

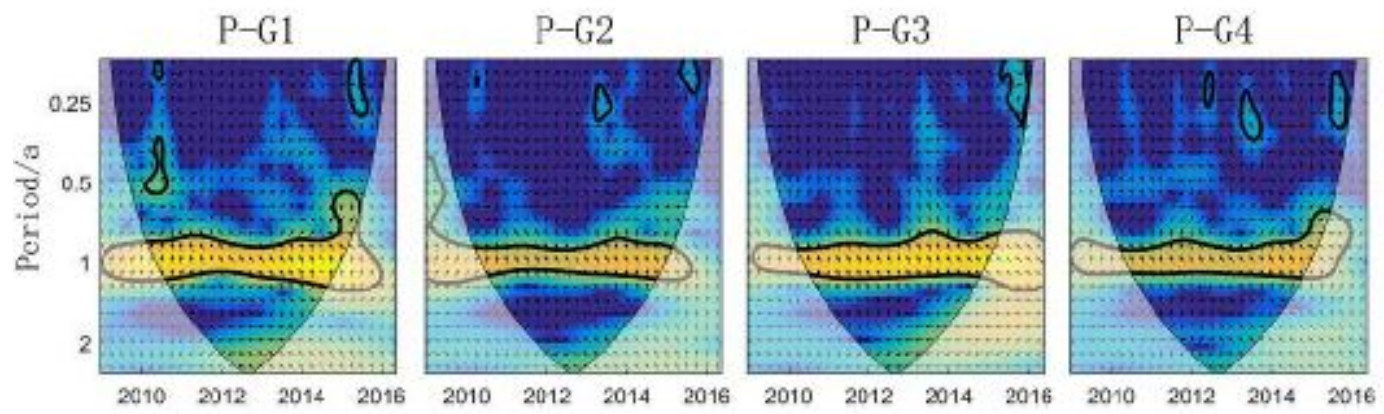

Note: The direction of the arrow diagram reflects the phase relationship between groundwater level and precipitation; the arrow from left to right indicates the same phase; the vertically downward direction says the wavelet transform of precipitation is in advance of $1 / 4$ underground water cycles, and vertically upward direction says the wavelet transform of precipitation is in advance of $3 / 4$ underground water level cycles. Other colors and symbolic meanings are the same as the continuous wavelet transform (Fig. 6).

Fig.7 Cross wavelet transforms of precipitation and groundwater levels

The precipitation and the groundwater level of each monitoring hole all have the main resonance period of about 1 year, and the significant periods outside the COI region are continuously distributed. The average time-lag of groundwater level in confined water monitoring hole to precipitation is 254.79 days and 253.73 days. The average time lag of water level of the phreatic water monitoring hole is 249.40 days and 244.08 days (Fig. 7, Tab. 2).

Tab.2 Periodicities and phases of cross wavelet transforms of precipitation and groundwater levels

\begin{tabular}{cccc}
\hline Group & Significant period (a) & Cross-phase (rad) & Time interval (d) \\
\hline P-G1 & $0.82-1.23$ & $4.3861 \pm 0.3823$ & $254.79 \pm 22.21$ \\
P-G2 & $0.82-1.16$ & $4.3678 \pm 0.2771$ & $253.73 \pm 16.10$ \\
P-G3 & $0.77-1.23$ & $4.2933 \pm 0.1915$ & $249.40 \pm 11.12$ \\
P-G4 & $0.77-1.09$ & $4.2016 \pm 0.2845$ & $244.08 \pm 16.53$ \\
\hline
\end{tabular}

From the full time cross wavelet transform, it can be seen that the precipitation time-lag period of phreatic water level is obviously shorter than that of confined water level. Therefore, the groundwater level change in the study area is greatly affected by precipitation. Therefore, the precipitation in the period precipitation and the groundwater level are cross transformed (Fig. 6), and the water level time-lag is calculated (Tab. 3).

\section{Cross Wavelet Transform of Temperature and Groundwater Level}

The cross wavelet transform of temperature and groundwater level of each monitoring hole are carried out to analyze its resonance period, significant time bucket and phase relationship (Fig. 8). 

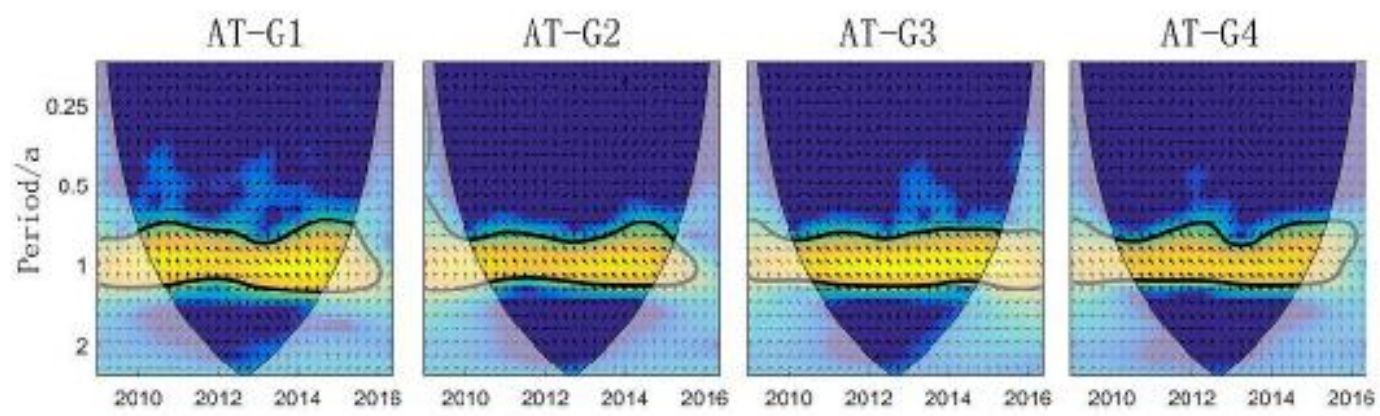

Fig.8 Cross wavelet transforms of air temperature and groundwater levels

The temperature and the underground water level of each monitoring hole all have the main resonance period of about 1 year, and the significant time buckets outside the COI region are continuously distributed. The average time-lag of groundwater level in confined water monitoring hole to precipitation is 236.56 days and 233.95 days. The average time-lag of phreatic water level is 233.40 days and 229.12 days (Fig. 6, Tab. 3). The time-lag of groundwater level to temperature in each monitoring hole is less than that of water level to precipitation.

Tab.3 Periodicities and phases of cross wavelet transforms of air temperature and groundwater levels

\begin{tabular}{cccc}
\hline Group & Significant period (a) & Cross-phase (rad) & Time interval (d) \\
\hline AT-G1 & $0.69-1.23$ & $4.0722 \pm 0.3406$ & $236.56 \pm 19.78$ \\
AT-G2 & $0.69-1.23$ & $4.0273 \pm 0.2875$ & $233.95 \pm 16.70$ \\
AT-G3 & $0.77-1.23$ & $4.0178 \pm 0.2036$ & $233.40 \pm 11.83$ \\
AT-G4 & $0.69-1.16$ & $3.9441 \pm 0.2284$ & $229.12 \pm 13.27$ \\
\hline
\end{tabular}

\section{Conclusions and Recommendations}

Based on the data analysis, the main fluctuation periods of monthly value sequence data of underground water level, precipitation and temperature in the monitoring holes around Chaiwopu Lake all are 1 year, and the main resonance periods between them are also1 year, and the significant periods of the cycle are basically the same.

During the whole period, the time-lag of phreatic water level in two holes to the precipitation is 249.40 days and 244.08 days, and the time-lag of confined water level in two holes to the precipitation is 254.79 days and 253.73 days. The influence in time-lag of precipitation on the phreatic water level in the study area is greater than that of confined water.

During the whole period, the time-lag of phreatic water level to the temperature is 233.40 days and 229.12 days, and the time-lag of confined water level to the temperature is 236.56 days and 233.59 days. The time-lag of water level in each monitoring holes to temperature is less than that of underground water level to precipitation. The shortening range of the time-lag of the phreatic water is less than that of defined water.

In this study, the statistical method is mainly used to analyze the time-lag relationship between groundwater level, precipitation and temperature. In later research, further analysis shall be made regarding the physical mechanism of interaction between the underground water level, precipitation and temperature, also shall include the impact of human activities on the underground water level, etc. 


\section{Acknowledgements}

This work was financially supported by the Monitoring and prediction of national geological environment (1210800000022), Develop standards about key technical for monitoring groundwater and its environment(201411074).

\section{References}

[1] LI Jun-li, HU Ru-ji, HUANG Yong, et al. Spatial-temporal Characterstics of Chaiwopu Lake Area Change and Its Driving Factors from 1964 to 2014 [J]. A R ID ZONE R ESEA R CH.2015.33(3):417-427.

[2] Chen Yanning, Xu Changchun, Yang Yuhui, et al. Hydrology and water resources variation and its responseces to regional climate change in Xinjiang[J]. Acta Geographica Sinica.2009,64

(11) : 1331-1341.

[3] CHAI Zheng, UMUT Halik, GOU Xin-hua, et al. Environmental Problems Caused by Excessive Exploitation of Groundwater at Chaiwopu Source in Xinjiang[J]. Research of Soil and Water Conservation. 2008,15(5):132-135.

[4] MA Long1, WU Jing-lu2, JILILI, et al. The Characteristics of Element Contents in Lacustrine Sediments and Surface Soils and Its Environmental Significances in Chaiwopu Region, Xinjiang, China[J]. JOURNAL OF NATURAL RESOURCES,2013.28(7):1221-1231.

[5] KUSS A J M, Gurdak J J. Groundwater level response in U.S. principal aquifers to ENSO, NAO, PDO, and AMO [J] . J Hydrol, 2014, 519 (B) : 1939-1952.

[6] MA Zhuguo, SHAO Lijuan. Relationship between dry/wet variation and the pacific decade oscillation (PDO) in northern China during the last 100 years $[\mathrm{J}]$. Chinese Journal of Atmospheric Sciences, 2006, 30 (3) : 464-474.

[7] XIAO Weiyu, WANG Lianxi, XUE Hongxi. The temporal and spatial change of extreme temperature and its association with AO index in Gansu province from 1959 to 2009 [ $\mathbf{J}$ ]. Journal of the Meteorological Sciences, 2013, 33 (2) : 190-195.

[8] GRINSTED A, MOORE J C, JEVREJEVA S. Application of the cross wavelet transform and wavelet coherence to geophysical time series[J]. Nonlinear Processes in Geophysics, 2004, 11(5-6): 561-566.

[9] NETO O P, PINTO I R C A, PINTO O J. The relationship between thunderstorm and solar activity for Brazil from 1951 to 2009 [J]. Journal of Atmospheric and Solar-Terrestrial Physics, 2013, 98:12-21.

[10] SHINE J M, HANDOJOSENO A M A, NGUYEN T N, et al. Abnormal patterns of theta frequency oscillations during the temporal evolution of freezing of gait in Parkinson's disease[J]. Clinical Neurophysiology, 2014, 125(3):569-576.

[11] LABAT D, ABABOU R, MANGIN A. Wavelet analysis in karstic hydrology. 2nd part: rainfall-runoff cross-wavelet analysis [J]. C. R. Acad. Sci., 1999, 329(12): 881-887.

[12] ADAMOWSKI J, CHAN H F. A wavelet neural network conjunction model for groundwater level forecasting [J]. Journal of Hydrology, 2011, 407(1-4): 28-40.

[13]QI Xiaofan, YANG Lizhi, HAN Ye, et al. Cross wavelet analysis of groundwater level regimes and precipitation-groundwater level regime in Ji'nan spring region[J]. Advances in Earth Science,2012,27(9): 969-978.

[14] QI Xiaofan, LI Wenpeng, YANG Lizhi, et al. The lag analysis of groundwater level anomalies to precipitation anomaly of Jinan springs watershed[J]. Earth and Environment,2015,43(6):619-627. 
[15] QI Xiaofan, WANG Yushan, YANG Lizhi, et al. Time lags variance of groundwater level response to precipitation of Jinan karst spring watershed in recent 50 years $[\mathrm{J}]$. Carsologica Sinica,2016,35(4):384-393.

[16]TREMBLAY L, LAROCQUE M, ANCTIL F, et al. Teleconnections and interannual variability in Canadian groundwater levels [J]. J Hydrol, 2011, 410(3-4): 178-188.

[17]KUSS A J M, GURDAK J J. Groundwater level response in U.S. principal aquifers to ENSO, NAO, PDO, and AMO [J]. J Hydrol, 2014, 519(B):1939-1952.

[18] QI Xiaofan, LI Wenpeng, LI Haitao, et al. Teleconnections between groundwater levels, precipitation, air temperature of the Jinan karst springs watershed and large scale climatic patterns[J]. Hydrogeology \& Engineering Geology,2015,42(6):18-28.

[19] QI Xiaofan, LI Wenpeng, LI Haitao, et al. Multiscale teleconnections between meteorological elements of Heihe River Basin and global climate indices[J]. Arid Land Geography,2017,40(3):564-572.

[20] Zhou Yangxiao, Li Wenpeng, et al. Regional groundwater flow modeling and sustainable development for groundwater resources[M]. Beijing, Science Press. 2011:24. 